\title{
Metal adsorption behavior of 2,4-dinitrophenyl hydrazine modified polyacrylonitrile nanofibers
}

\author{
S. Jitjaicham ${ }^{1}$, P. Kampalanonwat ${ }^{2}$, P. Supaphol ${ }^{*}$ \\ ${ }^{1}$ The Petroleum and Petrochemical College, Chulalongkorn University, Phyathai Road, Pathumwan, 10330 Bangkok, \\ Thailand \\ ${ }^{2}$ Rajamangala University of Technology Rattanakosin, Thanon Phutthamonthon Sai 5 Salaya Phutthamonthon Nakhon \\ 73170 Pathom, Thailand
}

Received 22 March 2013; accepted in revised form 18 June 2013

\begin{abstract}
Electrospun polyacrylonitrile nanofiber mats (es-PAN nanofiber mats) were surface modified by 2,4-dinitrophenyl-hydrazine (2,4-DNPH) to yield the metal ion adsorption material (es-PAN-DNPH nanofiber mats) and were investigated their adsorption behaviors. Functional modification of the es-PAN nanofiber mats and conventional polyacrylonitrile fibers (c-PAN fibers) were prepared by using $4 \%(\mathrm{w} / \mathrm{v})$ of 2,4-DNPH in 1,2-ethandiol at $110^{\circ} \mathrm{C}$ for $6 \mathrm{~h}$ to obtained c-PAN-DNPH fibers. The average diameter of the es-PAN-DNPH nanofiber mats was $0.25 \mu \mathrm{m}$, which was comparatively smaller than the es-PAN precursor. Their functional groups were confirmed by Fourier transform infrared spectroscopy (FT-IR) and their adsorption behaviors to trace $\mathrm{Ag}(\mathrm{I}), \mathrm{Bi}(\mathrm{III}), \mathrm{Ga}(\mathrm{III})$, and $\mathrm{In}(\mathrm{III})$ from aqueous solutions and were investigated by the induced couple plasma technique. The FT-IR spectra showed the existence of $\mathrm{NN}=\mathrm{C}-\mathrm{NHNH}-, \mathrm{O}=\mathrm{C}-\mathrm{NHNH}-$, and $-\mathrm{NO}_{2}$ functional groups for metal complexes. The adsorption capacities of the obtained es-PAN-DNPH were 7.14 to $36.36 \%$ higher than those of c-PAN-DNPH fibers. All adsorption plots onto es-PAN-DNPH nanofiber mats and c-PANDNPH fibers followed the Langmuir isotherm and indicated monolayer adsorption characteristics.
\end{abstract}

Keywords: nanomaterials, electrospinning, polyacrylonitrile (PAN)

\section{Introduction}

Because of current environmental awareness, trace element contaminants in natural water and discharged industrial effluents have been monitored to determine the accepted quantities [1]. Practices in water purification or waste water treatment are based on ion-exchange resins and fibers. The ion-exchange resins often contain specific functional ligands such as iminodiacetic acid (IDA) [2-4], amino-phosphonic acid [5], and amidoxime [6-9], which can readily react with heavy metal ions to form stable coordinate covalent bonds [4]. Fibrous ion-exchangers are characterized by a high specific surface site, good kinetic properties, and a ready-made structure of a variety of fibers for different fabrications [10,
11]. Most acrylonitrile-based synthetic fiber is made by reactions with specific aqueous reagents - 2aminoimidazole [12], aminourea [13], 2,4-dinitrophenylhydrazine [14], phenylhydrazine [15], and ethylenediamine [16] - to yield polyfunctional fibers for pre-concentration and separation of trace metal ions. Polymers based on the acrylonitrile group present reactive pendant cyano groups which can readily be modified by different kinds of reagents through nucleophilic addition and cyclo addition reactions [9]. A variety of chemically active textile materials based on polypropylene (PP) and polyacrylic have been developed for ion-exchange applications and under the registered trademark of FIBAN [17]. Additionally, Dominguez et al. [10] synthesized polyvinyl

\footnotetext{
${ }^{\text {*Corresponding author, e-mail: pitt.s@chula.ac.th }}$

(C) BME-PT
} 
alcohol mercaptyl fibers coated on fiberglass nonwoven mats for removing arsenite $\left(\mathrm{As}^{3+}\right)$ from water; Liao et al. [18] prepared an affinity membrane system on the basis of condensed tannins and natural collagen fiber membranes and investigated the adsorption-desorption behaviors of $\mathrm{UO}_{2}{ }^{2+}$. Nishiyama et al. [19] also prepared a chelated polyethylene porous hollow-fiber membrane containing an iminodiethanol (IDE) group whereas Yuan et al. [20] successively applied electrospun metal oxide- $\mathrm{TiO}_{2}$ nanofiber for elemental mercury removal from flue gas. Recently several researchers have utilized electrospun fibrous mat for ion removal [20-26].

The electrospun fibrous material is prepared by a simple method, namely electrostatic spinning technique. This electrospinning technique has proven to be relatively easy, shows adaptability, and versatility to fabricate non-woven fibrous mats with different forms of fibers- single fibers, hollow fibers, and sheath-core fibers [27-29]. Various polymers have been effectively electrospun under optimal conditions, which vary from polymer to solution properties, processing parameters, and ambient parameters. The electrospun nanofiber web contains porous structures with high porosity, inter-connectivity, micro interstitial spaces and a large surface-to-volume ration. Potential applications for the electrospun fibers range from material science and technology applications to life science and clinical medicine applications, environmental engineering applications to energy conservation, and biotechnology to defense and security applications where the high ratio of the surface area to mass is of primary importance $[27,28,30]$. The introduction of specific functional groups onto the electrospun nanofibers and composite nanofibers have been gaining attention for the removal of specific matters from aqueous solutions [20, 22, 31-33]. During the electrospinning process, a polymer droplet at the open end of a capillary is subjected to an electric field. Under applied electric field, the charge induced on the liquid surface causes reciprocal charge repulsion and subsequently destabilizes the pendant drop of polymer. Thus the rounded meniscus of the polymer droplet at the tip of the aperture elongates into a conical shape known as Taylor's cone [34]. At the critical electric field a repulsive electric force rises above the surface tension of the polymer. A charged jet of polymer is ejected from the apex of Taylor's cone and travels to a grounded collector. While the jet stream travels through the atmosphere, evaporation of solvent takes place leading to the deposition of solid polymer fibers on the collector [35]. Stretching and elongation of charged streams into a straight jet arises from gravitational, electrostatic, and Coulombic repulsion forces; entanglement of the polymer chains, surface tension, and drag forces prevent the jet from breaking up [36]. As a result, the electrically charged jet travels in a straight flight for a short distance before bending and splitting into ultrafine fibers, which randomly deposit in nonwoven patterns [37].

In the present study, electrospun poly(acryldinitrophenylamidrazone-ditnitro acrylphenylhydrazine) nanofibers mat (es-PAN-DNPH nanofiber mats) were prepared by chemical modification of the electrospun polyacrylonitrile (es-PAN), and conventional polyacrylonitrile (c-PAN) with 2,4-dinitrophenylhydrazine (DNPH) through a one-step process [14]. The es-PAN-DNPH chelating nanofiber mats possessed a large surface to volume mass. The functional groups in the fiber were verified by Fourier transform infrared spectroscopy (FT-IR) and fiber morphology was depicted by the scanning electron microscope (SEM). Inductively coupled plasma spectrometry (ICP) was employed to determine the adsorption capacities for the $\mathrm{Ag}(\mathrm{I}), \mathrm{Bi}(\mathrm{III}), \mathrm{Ga}(\mathrm{III})$, and In(III) ions, and their adsorption isotherms were also investigated. The recovery factors and adsorption kinetic behaviors of both the es-PAN-DNPH nanofiber mats and c-PAN-DNPH fibers were compared.

\section{Experimental}

\subsection{Materials and preparation}

Commercial grade of PAN fibers was obtained from Thai Acrylic Fibre Co., Ltd [conventional textile fiber, with diameters of individual fibers = $13.7 \pm 2.7 \mu \mathrm{m}$, containing acrylonitrile monomer and methylacrylate comonomer (91.4:8.6 wt \%) with $M_{\mathrm{W}}$ $55,500 \mathrm{~g} / \mathrm{mol}]$. All reagents used throughout the experiments were analytical-reagent grade without further purification. A mixed standard stock solution containing $\mathrm{Ag}, \mathrm{Bi}, \mathrm{Ga}$, and In ions, $100 \mathrm{ppm}$ each, was prepared by adding $10 \mathrm{~mL}$ of $1000 \mathrm{ppm}$ mixed standard ion solution and diluting to $100 \mathrm{~mL}$ with distilled water. 


\subsection{Electrospinning set-up for producing es-PAN nanofiber mats}

The electrospinning set-up in this work was basically similar to earlier studies [38]. A polymer solution, contained in a $10 \mathrm{~mL}$ standard glass syringe with a blunt-end stainless steel needle (gauge no. 20; OD $0.91 \mathrm{~mm}$ ), was used as a nozzle. The spinning geometry was $45^{\circ}$ from the horizontal baseline. A positive polarity electrode of a power supply (Gamma High Voltage Research D-ES30P-5W DC) was connected to the nozzle. The ground electrode was connected to the collective target- a rotating cylinder (OD $15 \mathrm{~cm}$, width $15 \mathrm{~cm}, \sim 40-50 \mathrm{rpm}$ ) wrapped with aluminum foil. Polyacrylonitrile in dimethylformamide solution $(10 \mathrm{wt} \%)$ was prepared for electrospinning under fixed processing parameters of $15 \mathrm{kV}$ of applied voltage, a $20 \mathrm{~cm}$ collecting distance and 48 hours of continuous spinning time.

\subsection{Preparation of PAN-DNPH fibers and nanofiber mats}

The preparation of PAN-DNPH fiber involved the conversion of the nitrile groups presented in the PAN fiber to the DNPH groups by using 2,4-DNPH as described by Chang et al. [14]. A $0.5 \mathrm{~g}$ piece of es-PAN nanofiber mats or c-PAN fibers were immersed in a flask containing $50 \mathrm{~mL}$ of $4 \%(\mathrm{w} / \mathrm{v})$ of 2,4-DNPH in 1,2-ethandiol solution and sealed. The mixture was placed in a temperature/time-controlled shaker bath and heated to $110^{\circ} \mathrm{C}$ and held there for $6 \mathrm{~h}$. After the reaction complete, the product was extracted with absolute alcohol to remove free agents, then washed with distilled water until neutral $\left(\mathrm{pH} \mathrm{7.0)}\right.$ and dried in an oven $\left(60^{\circ} \mathrm{C}\right.$, overnight). The reaction is depicted in Figure 1.

\subsection{Characterization of es-PAN and es-PAN-DNPH chelating nanofiber mats}

The morphology of the obtained nanofiber mats were investigated using a JEOL JSM-6400 scanning electron microscope (SEM) and SemAfore 4.0 software. The functional groups of the nanofiber mats were characterized by a FT-IR spectroscopy (Perkin-Elmer Spectrum 100 and Spectrum software) at a resolution of $4 \mathrm{~cm}^{-1}$ and a wavenumber range of 4000 to $650 \mathrm{~cm}^{-1}$. The adsorption capacities of es-PAN$\mathrm{DNPH}$ to $\mathrm{Ag}, \mathrm{Bi}, \mathrm{Ga}$, and In ions were determined by an inductively coupled plasma atomic emission spectrometer (ICP-AES, PerkinElmer Plasma-1000).

\subsection{Effect of initial pH on metal ions adsorption onto es-PAN-DNPH chelating nanofiber mats}

The mixed standard stock solutions containing certain metal ions (Ag, $\mathrm{Bi}, \mathrm{Ga}$, and In ions) were adjusted to $\mathrm{pH} 2-6$, and $\mathrm{pH} 4.5$ with $0.1 \mathrm{M} \mathrm{HCl}$. Then effect of the initial $\mathrm{pH}$ on metal ions adsorption were investigated by placing $30 \mathrm{mg}$ of es-PANDNPH mat in each bottle containing $10 \mathrm{~mL}$ of a $100 \mathrm{ppm}$ mixed standard stock solution at various $\mathrm{pH}$ ranges. The mixtures were shaken at $30^{\circ} \mathrm{C}$ for 24 hours in a shaker bath with a shaker speed of $100 \mathrm{rpm}$. The amounts of $\mathrm{Ag}, \mathrm{Bi}, \mathrm{Ga}$, and In ions adsorbed onto the es-PAN-DNPH nanofiber mats were verified from the initial and final concentrations of the metal ions in the aqueous solutions. The residual concentration of $\mathrm{Ag}, \mathrm{Bi}, \mathrm{Ga}$, and In ions in the solutions were determined by ICP spectrometry, and the adsorption capacity $[\mathrm{mg} / \mathrm{g}]$ of es-PAN$\mathrm{DNPH}$ to $\mathrm{Ag}, \mathrm{Bi}, \mathrm{Ga}$, and In ions were calculated using Equation (1) [35]:

$$
q=\frac{\left(C_{0}-C_{\mathrm{e}}\right) V}{M}
$$

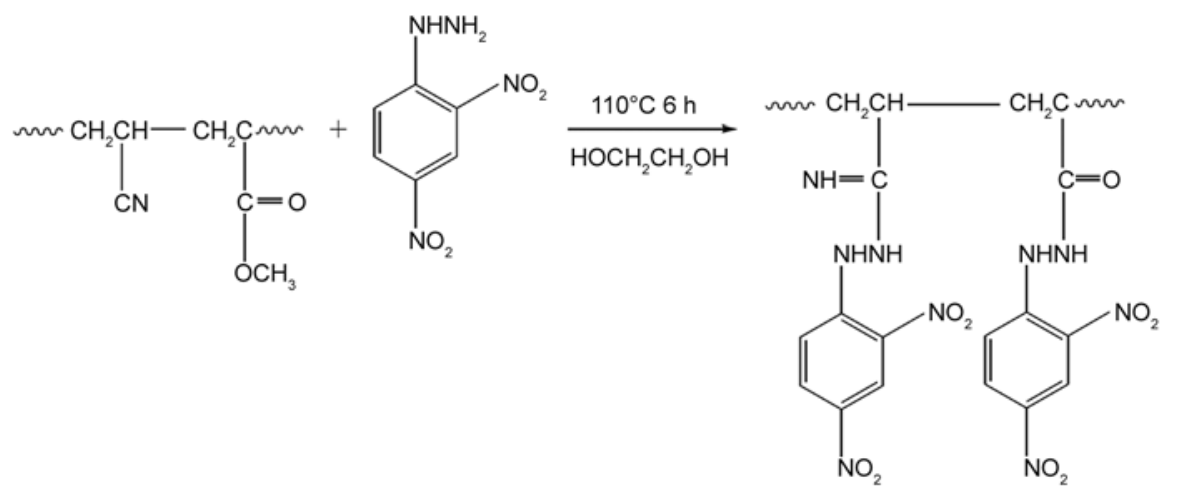

Figure 1. Reaction of es-PAN with 2,4-DNPH to produce poly(acryldinitrophenyl amidrazone-dinitroacrylphenylhydrazine) 
where $q$ is the amount adsorbed $[\mathrm{mg} / \mathrm{g}], C_{0}$ is the initial metal-ion concentration $[\mathrm{mg} / \mathrm{L}], C_{\mathrm{e}}$ is the equilibrium metal-ion concentration $[\mathrm{mg} / \mathrm{L}], V$ is the solution volume [L], and $t^{\prime}$ is the amount of adsorbent used $[\mathrm{g}]$.

\subsection{The recovery factors, adsorption kinetics and equilibrium isotherm of metal ions onto PAN-DNPH fibers and nanofiber mats}

Dried samples of PAN-DNPH fibers or nanofiber mats $(0.1 \mathrm{~g})$ were shaken in $20 \mathrm{~mL}$ mixed standard metal ions stock solution (containing $200 \mathrm{ppm}$ of $\mathrm{Ag}, \mathrm{Bi}, \mathrm{Ga}$, and In ions each) by the batch technique for different time durations at $30^{\circ} \mathrm{C}$ for 24 hours.

The rate constant of adsorption was calculated using Equation (2):

$-\ln (1-F)=K t$

where $F$ is $q_{\mathrm{t}} / q_{\mathrm{e}}$ and $q_{\mathrm{e}}$ is the saturation adsorption capacity $[\mathrm{mg} / \mathrm{g}], q_{\mathrm{t}}$ is the adsorption capacity at $t$ $\min [\mathrm{mg} / \mathrm{g}], K$ is the rate constant.

Equilibrium adsorption isotherms were also studied as a function of the concentration of the metal ion stock solutions (20-300 ppm of Ag, Bi, Ga, and In ions each) at $30^{\circ} \mathrm{C}$ for 24 hours. After equilibration, the concentrations of the different metal ions in the solutions were determined by ICP spectrometer. The adsorption equilibrium [mg/g] of PAN-DNPH to $\mathrm{Ag}(\mathrm{I}), \mathrm{Bi}(\mathrm{III}), \mathrm{Ga}(\mathrm{III})$, and $\mathrm{In}(\mathrm{III})$ ions were analyzed according to the Langmuir adsorption isotherm Equation (3) as follows:

$$
\frac{C_{\mathrm{e}}}{q_{\mathrm{e}}}=\frac{1}{K_{\mathrm{L}} q_{\mathrm{m}}}+\frac{C_{\mathrm{e}}}{q_{\mathrm{m}}}
$$

where $q_{\mathrm{e}}$ is the equilibrium quantity of the metal adsorbed on the PAN-DNPH chelating fiber $[\mathrm{mg} / \mathrm{g}]$, $C_{\mathrm{e}}$ is the equilibrium concentration $[\mathrm{mg} / \mathrm{L}]$, and $q_{\mathrm{m}}$ and $K_{\mathrm{L}}$ are the maximal adsorption capacity of the metal ions on the adsorbent $[\mathrm{mg} / \mathrm{g}]$ and the adsorption equilibrium constant $[\mathrm{mL} / \mathrm{mg}]$, respectively.

The recovery factor of each metal ion is calculated with Equation (4) [6]:

$$
\% R=\frac{C_{\mathrm{a}}}{C_{0}} \cdot 100
$$

where $\% R$ is the recovery factor, $C_{\mathrm{a}}$, the amount of metal ion adsorbed, is calculated from the differ- ence between the initial concentration $\left(C_{0}\right)$ and the residual concentration at equilibrium $\left(C_{\mathrm{e}}\right)$.

\section{Results and discussion}

PAN-DNPH chelating fiber synthesized from PAN fibers was effectively used for enrichment and separation of traces of metal ions from solution samples.

\subsection{Characterization of es-PAN and es-PAN-DNPH chelating nanofiber mats}

The FT-IR spectra (Figure 2) of es-PAN nanofiber mat exhibits characteristic bands of nitrile (2243 $\left.\mathrm{cm}^{-1}\right)$, carbonyl $\left(1732 \mathrm{~cm}^{-1}\right)$, and ether $(\sim 1201$ and $\sim 1172-1071 \mathrm{~cm}^{-1}$ ) groups; carbonyl and ether bands came from the methylacrylate comonomer [31]. The FT-IR spectra of es-PAN-DNPH shows all the characteristic bands of the functional groups of es-PAN with additional peaks around 3400 to $3200 \mathrm{~cm}^{-1}$ (the stretching vibration of $\mathrm{NH},=\mathrm{NH}$ or $\mathrm{Ar}-\mathrm{NH}), 1539 \mathrm{~cm}^{-1}$ [the asymmetric stretching vibration of $\left.\mathrm{NO}_{2}(\mathrm{Ar})\right], 1520 \mathrm{~cm}^{-1}$ (the rocking bending vibration of $=\mathrm{NH}$ ), $1223 \mathrm{~cm}^{-1}$ (the stretching vibration of $\mathrm{C}-\mathrm{N}$, or $\mathrm{N}-\mathrm{C}=\mathrm{O}$ ), $923 \mathrm{~cm}^{-1}$ (the twisting bending vibration of $\mathrm{NH}$ or $=\mathrm{NH}$ ), and $835 \mathrm{~cm}^{-1}$ (the bending vibration of $\mathrm{C}-\mathrm{NO}_{2}$ ), respectively [14]. The intensity of the nitrile $\left(2243 \mathrm{~cm}^{-1}\right)$ and carbonyl $\left(1732 \mathrm{~cm}^{-1}\right)$ peaks of es-PAN decreased with the introduction of dinitrophenylhydrazine by chemical treatment of the acrylonitrile and methylacrylate groups. From the FT-IR spectra of the esPAN-DNPH nanofiber mats, the introduction of DNPH groups onto es-PAN nanofiber mats was confirmed.

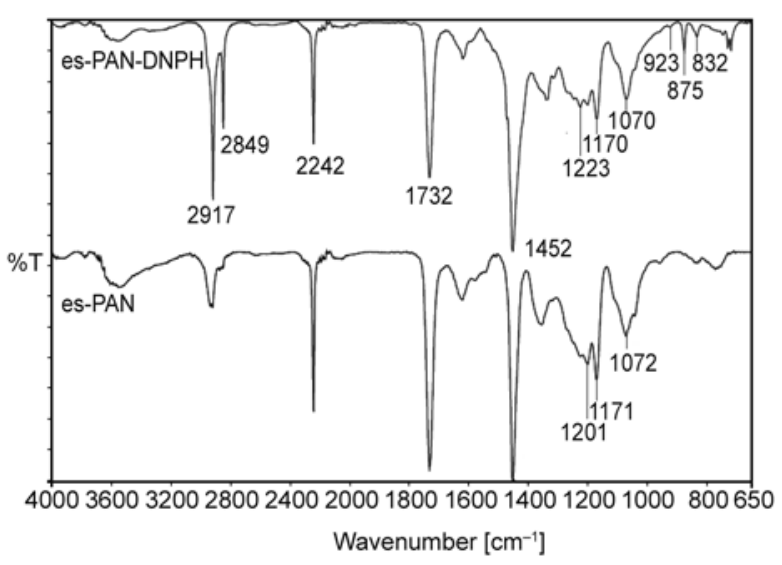

Figure 2. The FT-IR spectra of the es-PAN, and es-PANDNPH chelating nanofiber 


\subsection{Morphologies of the es-PAN and es-PAN- DNPH nanofiber mats}

Under the applied electrospinning set-up, smooth continuous fiber webs were obtained with the diameter of the fibers ranging from 0.31 to $0.49 \mu \mathrm{m}$ (Figure $3 \mathrm{a}$ ). The surface of the es-PAN-DNPH nanofiber mats were still smooth, similar to those of the original es-PAN, but the average diameter of the obtained es-PAN-DNPH nanofiber mats were $0.25 \mu \mathrm{m}(0.16$ to $0.29 \mu \mathrm{m})$, which was a $\sim 40 \%$ reduction (Figure $3 b$ ). This reduction in diameter was a consequence of the high temperature treatment resulting in the shrinking of fiber diameter [39]. The es-PAN-DNPH were used as adsorption media by immersing them in a mixed metal ion standard solution for $24 \mathrm{~h}$, the webs shrunk and become denser. However, the average fiber diameter of the es-PAN-DNPH after metal solution adsorption was $0.23 \mu \mathrm{m}(0.15$ to $0.34 \mu \mathrm{m})$ which was comparable to their precursors (Figure $3 \mathrm{c}$ ).

\subsection{Effect of initial $\mathrm{pH}$ on metal ions adsorption onto es-PAN-DNPH chelating nanofiber mats}

DNPH modified-PAN showed relatively high recoveries (more than $92 \%$ ) of trace metal ions ( $\mathrm{Au}, \mathrm{Ru}$, In, $\mathrm{Bi}, \mathrm{Zr}, \mathrm{V}, \mathrm{Ga}$, and $\mathrm{Ti}$ ions) at $\mathrm{pH} 4-5$ [14]. Thus, the $\mathrm{pH}$ range of $2-6$ and $\mathrm{pH} 4.5$ were employed to study the effect of the initial $\mathrm{pH}$ on the adsorption of $\mathrm{Ag}(\mathrm{I}), \mathrm{Bi}(\mathrm{III}), \mathrm{Ga}(\mathrm{III})$, and $\mathrm{In}(\mathrm{III})$ onto the esPAN-DNPH chelating nanofiber mats. Due to the protonation and deprotonation properties of the functional groups in the es-PAN-DNPH, Figure 4 shows that the initial $\mathrm{pH}$ effects the adsorption properties of the es-PAN-DNPH in a slightly different manner. In most cases, the adsorption amounts were small at $<\mathrm{pH} 4$, then increasing to $\sim \mathrm{pH} 4.5$. At $\mathrm{pH}$ values higher than 5, the adsorption of $\mathrm{Ag}(\mathrm{I}), \mathrm{Ga}(\mathrm{III})$, and In(III) decreased, whereas that of $\mathrm{Bi}(\mathrm{III})$ continuously increased to $\mathrm{pH} 6$. At $\mathrm{pH} 2, \mathrm{H}^{+}$from the solution could readily occupy the surface of es-PAN$\mathrm{DNPH}$, resulting in a repulsive barrier to the metal cations; thus, small amounts of metal ions were adsorbed. At pH 4 the metal adsorption increased considerably because the attraction between the positive charges of the metal ions and the lone-pair electrons of the nitrogen ligands overcame the
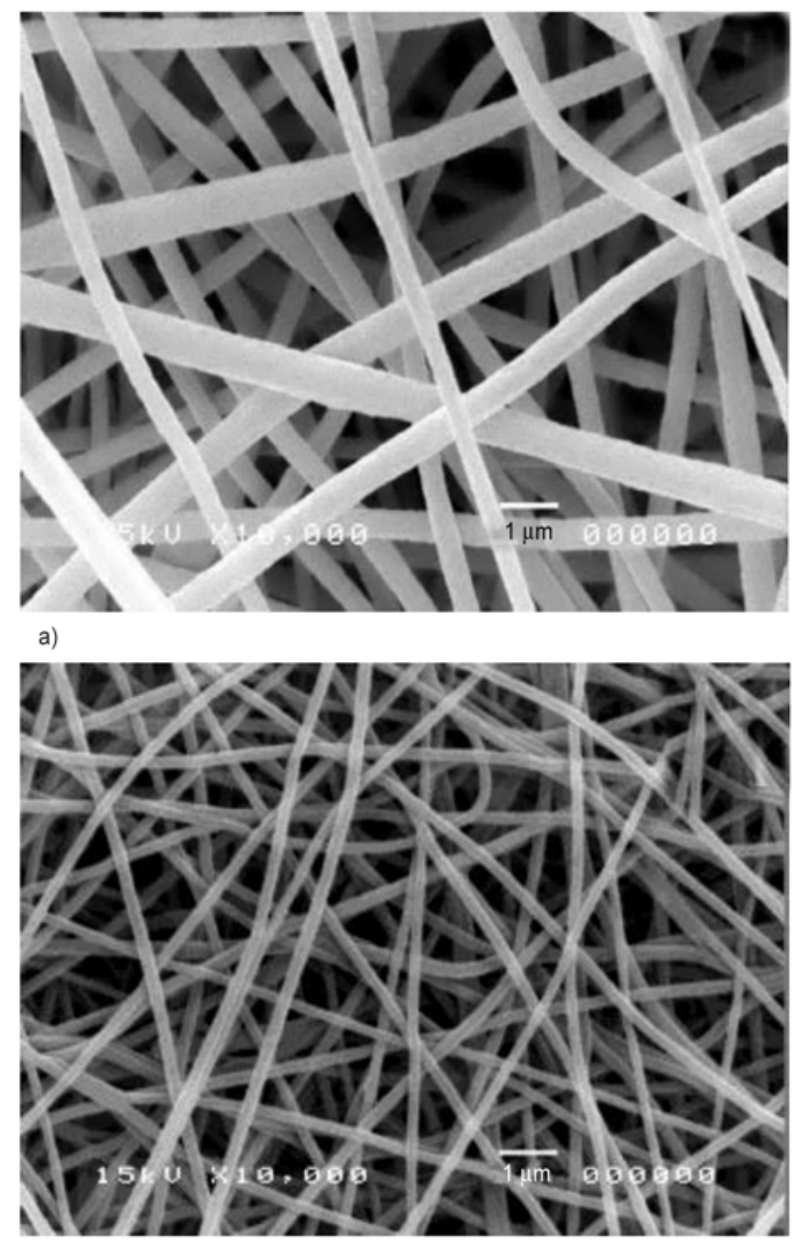

b)

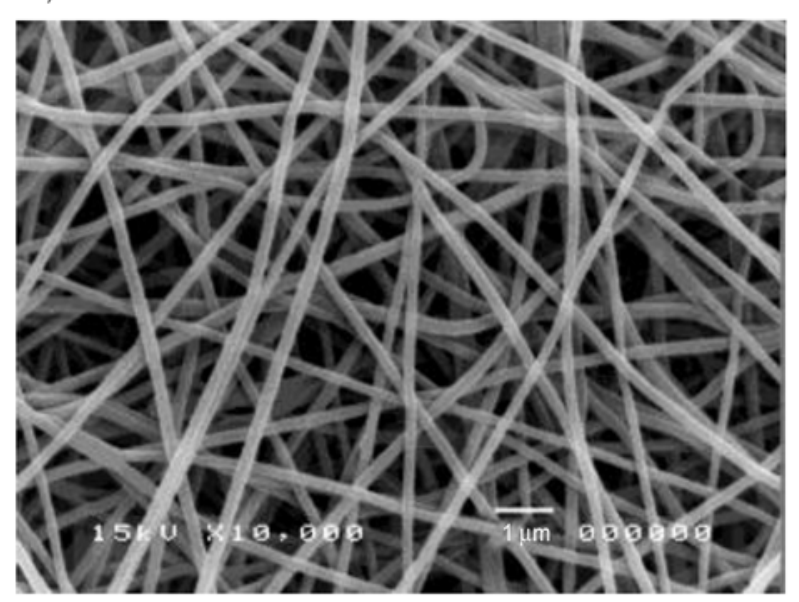

c)

Figure 3. SEM images: (a) es-PAN, (b) es-PAN-DNPH nanofiber mats, and (c) es-PAN-DNPH fibers after adsorption of the metal solution

repulsive protonation. Beyond $\mathrm{pH} 5$ the concentration of $\mathrm{OH}^{-}$was high enough to interact with the free metal ions, thus the amount of adsorbed metal ions decreased. 


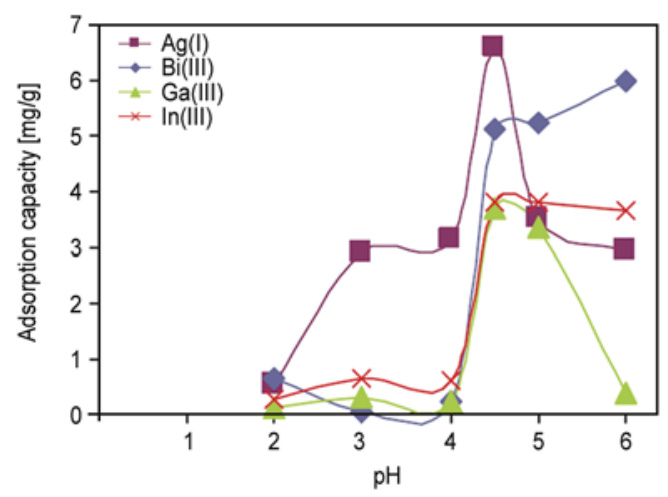

Figure 4. The effect of initial $\mathrm{pH}$ on the adsorption of $\mathrm{Ag}(\mathrm{I})$, $\mathrm{Bi}(\mathrm{III}), \mathrm{Ga}(\mathrm{III})$, and $\mathrm{In}(\mathrm{III})$ onto the es-PANDNPH chelating nanofiber mats

\subsection{Recovery factors, adsorption kinetics and equilibrium isotherm of the metal ions onto PAN-DNPH chelating fiber}

The adsorption capacities of $\mathrm{Ag}(\mathrm{I}), \mathrm{Bi}(\mathrm{III}), \mathrm{Ga}(\mathrm{III})$, and In(III) onto the es-PAN-DNPH nanofiber mats and c-PAN-DNPH fibers in a $200 \mathrm{ppm}$ mixed standard stock solution as a function of time (to 24 hours) were depicted in $\mathrm{mg} / \mathrm{g}$ (Figure 5). The equilibrium adsorption of $\mathrm{Ag}(\mathrm{I}), \mathrm{Bi}(\mathrm{III}), \mathrm{Ga}(\mathrm{III})$, and $\operatorname{In}(\mathrm{III})$ onto the es-PAN-DNPH were 0.045 , $0.030,0.042$ and 0.023 mmole, respectively, where those onto the c-PAN-DNPH were $0.042,0.022$, 0.038 and 0.019 mmole, respectively (Table 1 ).

The adsorption of $\mathrm{Ag}(\mathrm{I})$ and $\mathrm{Bi}(\mathrm{III})$ onto both the es-PAN-DNPH and the c-PAN-DNPH increased

Table 1. Maximum adsorption capacities of es-PAN-DNPH and c-PAN-DNPH to metal ions

\begin{tabular}{|l|c|c|c|c|}
\hline \multirow{2}{*}{$\begin{array}{c}\text { Metal ions } \\
\text { adsorbed }\end{array}$} & \multicolumn{2}{|c|}{ es-PAN-DNPH } & \multicolumn{2}{c|}{ c-PAN-DNPH } \\
\cline { 2 - 5 } & {$[\mathbf{m g} / \mathbf{g}]$} & {$[\mathbf{m m o l e} / \mathbf{g}]$} & {$[\mathbf{m g} / \mathbf{g}]$} & [mmole/g] \\
\hline $\mathrm{Ag}(\mathrm{I})$ & 4.865 & 0.045 & 4.481 & 0.042 \\
\hline $\mathrm{Bi}(\mathrm{III})$ & 6.309 & 0.030 & 4.685 & 0.022 \\
\hline $\mathrm{Ga}(\mathrm{III})$ & 2.960 & 0.042 & 2.666 & 0.038 \\
\hline $\mathrm{In}(\mathrm{III})$ & 2.630 & 0.023 & 2.173 & 0.019 \\
\hline
\end{tabular}

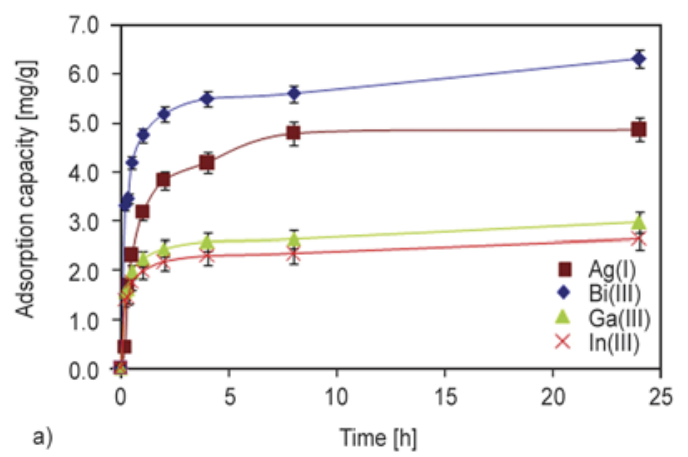

more sharply than $\mathrm{Ga}(\mathrm{III})$ and $\mathrm{In}(\mathrm{III})$ in the first 2 hours. After 8 hours, the adsorption capacity of the metal ions leveled off. The increases to 8 hours were attributed to the free binding sites on the surface of the adsorbents, after those binding sites were occupied, the adsorption capacities became saturated. The saturated adsorption capacities decreased in the following sequence: $\mathrm{Bi}$ (III) $>\mathrm{Ag}$ (I) $>\mathrm{Ga}$ (III) $>\operatorname{In}(\mathrm{III})$, which corresponded to the electronegativity value of each metal $2.02>1.93>1.81>1.78$, respectively. However, $0.045 \mathrm{mmole} / \mathrm{g}$ of $\mathrm{Ag}(\mathrm{I})$, which was the highest, absorbed onto the es-PANDNPH and $0.042 \mathrm{mmole} / \mathrm{g}$ of $\mathrm{Ag}(\mathrm{I})$ absorbed onto the c-PAN-DNPH. This might due to the $1: 1 \mathrm{com}-$ plexation between metal ion group IB of the periodic table and es-PAN-DNPH. The amount of Ga(III) adsorbed onto the es-PAN-DNPH was nearly 2 times higher than the adsorbed In(III) [though both Ga(III) and In(III) are metal ions in the same group (IIIA) of the periodic table]. This might be due to the lighter molecular mass of $\mathrm{Ga}(\mathrm{III})$, which led to fast, easy adsorption. According to Liu et al. [11], the binding capacity of the chelating ion exchange media for each metal ion depends on the affinity of the functional groups towards the metal ion. The strength of the affinity can be expressed as the complex formation constant.

The adsorption kinetics of $\mathrm{Ag}(\mathrm{I}), \mathrm{Bi}(\mathrm{III}), \mathrm{Ga}(\mathrm{III})$, and $\mathrm{In}(\mathrm{III})$ onto the es-PAN-DNPH can be determined from the slope of the plot between $-\ln (1-F)$ in relation to time (Figure 6). It was found that the adsorption rate of $\mathrm{Ag}(\mathrm{I})>\mathrm{Bi}(\mathrm{III}) \sim \mathrm{In}(\mathrm{III}) \sim \mathrm{Ga}(\mathrm{III})$ (values were shown in Table 2). It is possibly because $\mathrm{Ag}(\mathrm{I})$ has the largest ionic radius of $115 \mathrm{pm}$ [Bi(III) 103 pm, In(III) 80 pm, Ga(III) 62 pm]. The adsorption kinetics of $\mathrm{Ag}(\mathrm{I}), \mathrm{Bi}(\mathrm{III}), \mathrm{Ga}(\mathrm{III})$, and $\mathrm{In}(\mathrm{III})$ onto the c-PAN-DNPH are depicted in Figure 7. It was found that the adsorption rate of $\mathrm{Ag}(\mathrm{I})>\mathrm{Bi}$ (III)

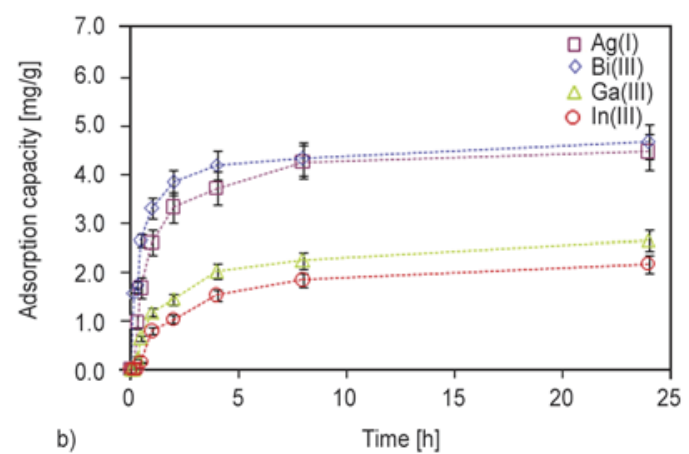

Figure 5. The adsorption of $\mathrm{Ag}(\mathrm{I}), \mathrm{Bi}(\mathrm{III}), \mathrm{Ga}(\mathrm{III})$, and $\mathrm{In}(\mathrm{III})$ onto (a) the es-PAN-DNPH nanofiber mats, and (b) c-PANDNPH fibers as a function of time (to 24 hours) 

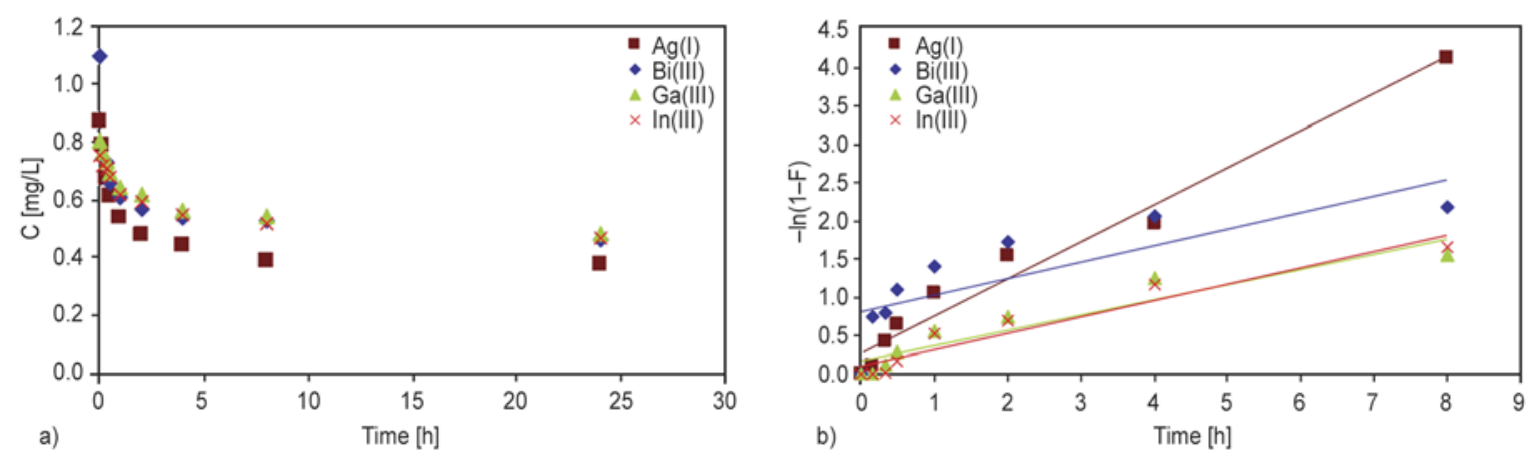

Figure 6. (a) metal ions solution concentration and (b) the adsorption kinetic of metal ions onto the es-PAN-DNPH nanofiber mats as a function of time (to $24 \mathrm{hrs}$ )

Table 2. Rate constant of metal ion adsorption onto the esPAN-DNPH and c-PAN-DNPH chelating fiber

\begin{tabular}{|c|c|c|c|c|}
\hline \multirow[b]{2}{*}{$\begin{array}{l}\text { Metal ion } \\
\text { adsorbed }\end{array}$} & \multicolumn{2}{|c|}{ es-PAN-DNPH } & \multicolumn{2}{|c|}{ c-PAN-DNPH } \\
\hline & $\begin{array}{c}\text { Rate constant } \\
{\left[\mathrm{hr}^{-1}\right]}\end{array}$ & $\mathbf{R}^{2}$ & $\begin{array}{c}\text { Rate constant } \\
{\left[\mathrm{hr}^{-1}\right]}\end{array}$ & $\mathbf{R}^{2}$ \\
\hline $\operatorname{Ag}(\mathrm{I})$ & 0.484 & 0.9693 & 0.371 & 0.9468 \\
\hline $\mathrm{Bi}(\mathrm{III})$ & 0.215 & 0.6446 & 0.291 & 0.7860 \\
\hline Ga(III) & 0.199 & 0.8875 & 0.241 & 0.9164 \\
\hline In(III) & 0.214 & 0.9283 & 0.252 & 0.9650 \\
\hline
\end{tabular}

$\sim \mathrm{In}(\mathrm{III}) \sim \mathrm{Ga}$ (III) onto the c-PAN-DNPH was similar to the es-PAN-DNPH.

Figure 8 illustrates the equilibrium adsorption isotherm (24 hours of adsorption time) and Langmuir

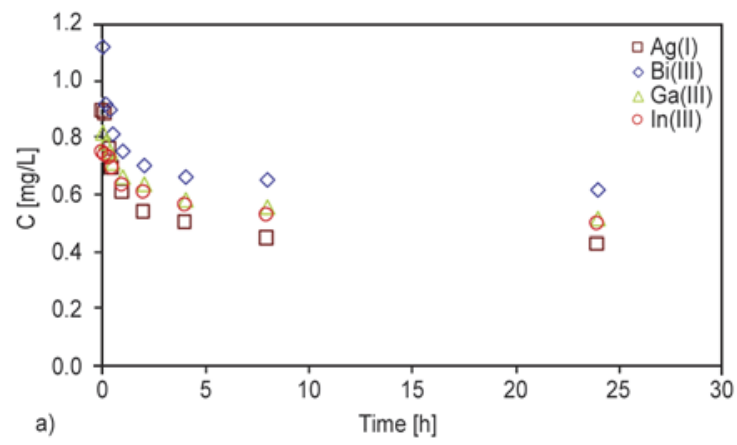

plot of $\mathrm{Ag}(\mathrm{I}), \mathrm{Bi}(\mathrm{III}), \mathrm{Ga}(\mathrm{III})$, and $\mathrm{In}(\mathrm{III})$ ion onto the es-PAN-DNPH chelating nanofiber mats under various equilibrium concentrations ( $20-300 \mathrm{ppm})$. The formation of chelated structure between the metal ions and the es-PAN-DNPH (Figure 9) may be comparable with $\mathrm{Ga}(\mathrm{III})$ or In(III) - poly(acryl-phenylamidrazonephenylhydrazide) chelated complexes as reported by Chang et al. [16]. Because of the combination of nitrogen atoms in $\mathrm{N}-\mathrm{H}$ and $=\mathrm{N}-\mathrm{H}$, and of oxygen atom in $\mathrm{O}=\mathrm{C}-\mathrm{N}$ with $\mathrm{Ga}(\mathrm{III})$ and In(III) to form cyclic compounds. The Langmuir constant qm and $K_{\mathrm{L}}$ in Table 3 are calculated from the slope and intercept of the $C_{\mathrm{e}} / q_{\mathrm{e}}$ versus $C_{\mathrm{e}}$ plot.

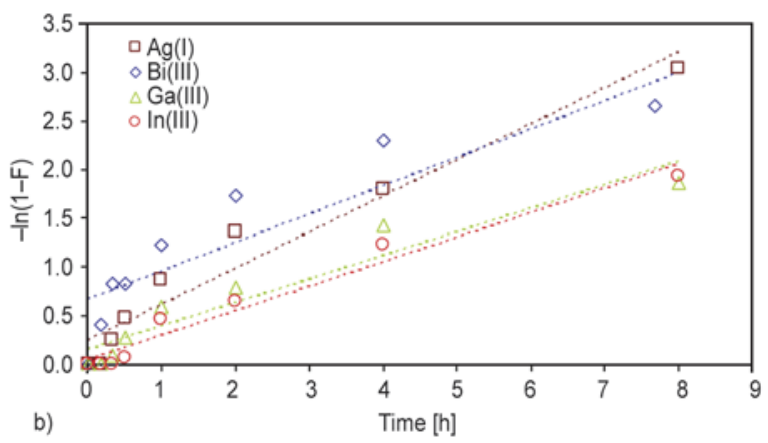

Figure 7. (a) metal ions solution concentration and (b) the adsorption kinetic of metal ions onto the c-PAN-DNPH fibers as a function of time (to $24 \mathrm{hrs}$ )
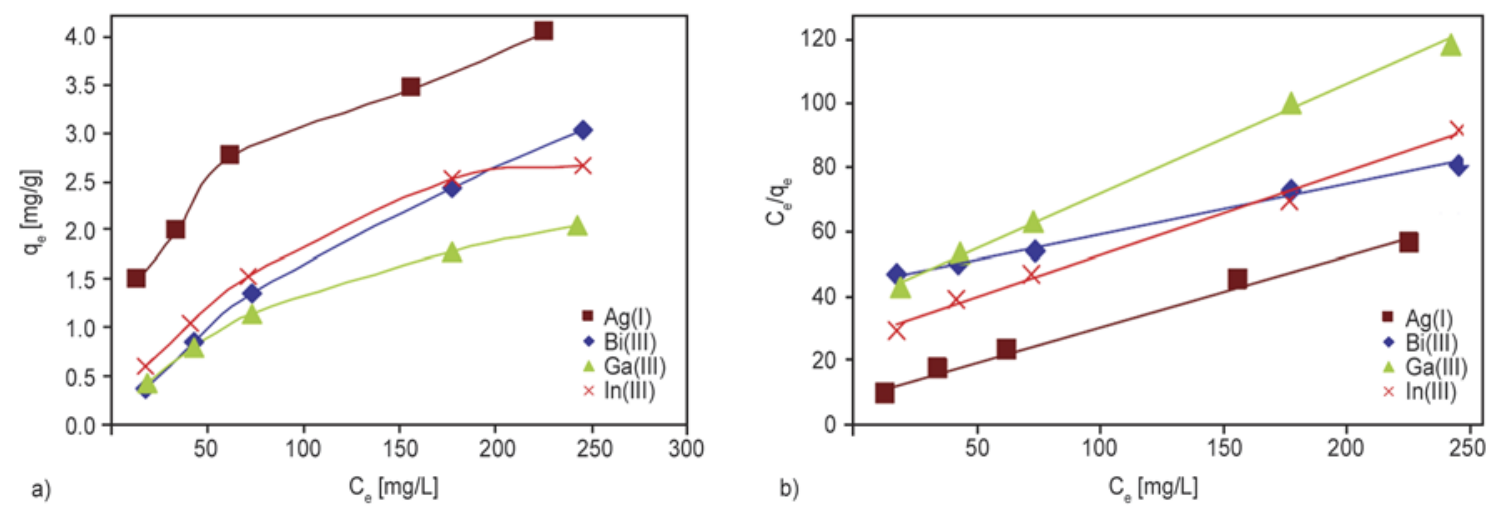

Figure 8. (a) Equilibrium adsorption isotherm of metal ions and (b) Langmuir plot of metal ions onto the es-PAN-DNPH nanofiber mats 


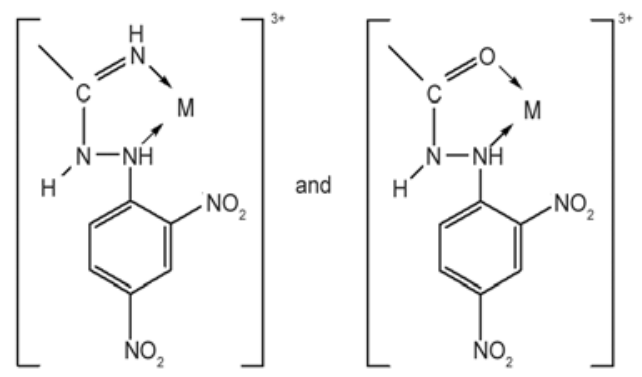

Figure 9. The formation of chelate structure between metal ions and the es-PAN-DNPH nanofiber mats

Table 3. Langmuir isotherm constants and correlation coefficients of metal ion adsorption onto the es-PANDNPH nanofiber mats

\begin{tabular}{|l|c|c|c|}
\hline \multirow{2}{*}{$\begin{array}{c}\text { Metal ion } \\
\text { adsorbed }\end{array}$} & \multicolumn{3}{|c|}{ Langmuir model } \\
\cline { 2 - 4 } & $\begin{array}{c}\mathbf{q}_{\mathbf{m}} \\
{[\mathbf{m g} / \mathbf{g}]}\end{array}$ & $\begin{array}{c}\mathbf{K}_{\mathbf{L}} \\
{[\mathbf{m} \mathbf{L} / \mathbf{m g}]}\end{array}$ & $\mathbf{R}^{\mathbf{2}}$ \\
\hline $\mathrm{Ag}(\mathrm{I})$ & 4.587 & 0.026 & 0.9887 \\
\hline $\mathrm{Bi}(\mathrm{III})$ & 6.494 & 0.004 & 0.9951 \\
\hline $\mathrm{Ga}(\mathrm{III})$ & 2.959 & 0.009 & 0.9977 \\
\hline $\mathrm{In}(\mathrm{III})$ & 3.861 & 0.010 & 0.9929 \\
\hline
\end{tabular}

The linear plot indicates that of all observed metal ions, adsorption followed the Langmuir isotherm. The basic assumption of the Langmuir theory is that adsorption takes place at specific homogeneous sites within the adsorbent [32]. The saturated adsorption constant, qm of metal ions onto the es-PANDNPH were $\mathrm{Bi}(\mathrm{III})>\mathrm{Ag}(\mathrm{I})>\operatorname{In}(\mathrm{III})>\mathrm{Ga}(\mathrm{III})$. The saturated adsorption capacities of $\mathrm{Bi}$ (III) onto the es-PAN-DNPH were the highest. However, $K_{\mathrm{L}}$ of $\mathrm{Ag}(\mathrm{I})$ onto the es-PAN-DNPH were the highest, which revealed binding energy of $\mathrm{Ag}(\mathrm{I})$ to this specifically modified fiber. It is assumed that once a metalion occupied a reaction site, no further adsorption can occur at that location.

The recovery factor of $\mathrm{Bi}(\mathrm{III}), \mathrm{Ag}(\mathrm{I}), \mathrm{Ga}(\mathrm{III})$, and In(III) onto the es-PAN-DNPH were 58.01, 56.57, 39.85 , and $38.12 \%$, respectively, which were about half less than those reported by continuous flow process. The recovery factor of $\mathrm{Bi}(\mathrm{III}), \mathrm{Ag}(\mathrm{I})$, $\mathrm{Ga}(\mathrm{III})$, and $\mathrm{In}(\mathrm{III})$ onto the c-PAN-DNPH were $45.15,52.50,36.85$, and $33.70 \%$, respectively. It was found that a high surface to volume ratio of the es-PAN-DNPH directly resulted in a higher recovery factor. Though there were large area of contact between the metal ions and the modified electrospun fiber mat, but the es-PAN-DNPH shrank when immersed in the solution. The saturated adsorption capacities of $\operatorname{Ag}(\mathrm{I})$ and $\mathrm{Bi}(\mathrm{III})$ onto the c-PANDNPH were lower than the es-PAN-DNPH results.

\section{Conclusions}

The es-PAN-DNPH nanofiber mats were successfully prepared by electrospinning a solution of conventional PAN fibers and converting the nitrile groups present in the fiber into metal ion affinity functional groups by chemical modification with 2,4-DNPH. The FT-IR spectra revealed the existence of $\mathrm{NN}=\mathrm{C}-\mathrm{NHNH}-, \mathrm{O}=\mathrm{C}-\mathrm{NHNH}-$, and $-\mathrm{NO}_{2}$ functional groups for metal complexes. Certain metal ions - Ag(I), Bi(III), Ga(III), and In(III) were adsorbed, with the initial $\mathrm{pH}$ of 4.5 being the optimal value where the es-PAN-DNPH nanofiber mats showed high adsorption toward all four types of the metal ions. The saturated adsorption capacities decreased as $\mathrm{Bi}(\mathrm{III})>\mathrm{Ag}(\mathrm{I})>\mathrm{Ga}(\mathrm{III})>\mathrm{In}(\mathrm{III})$, which corresponded to the electronegativity value of each metal. The adsorption of these metal ions was fitted well with the Langmuir equation, with the maximal adsorption capacities being 6.50, 4.59, 2.96 and $3.87 \mathrm{mg} \cdot \mathrm{g}^{-1}$ for $\mathrm{Bi}$ (III), $\mathrm{Ag}(\mathrm{I}), \mathrm{Ga}(\mathrm{III})$ and In(III) ions, respectively, indicating monolayer adsorption manner. The obtained results suggested that the es-PAN-DNPH nanofiber mats possess a tremendous potential for use as an adsorbent for metal ions in wastewater effluents.

\section{Acknowledgements}

The authors acknowledge support from the Petroleum and Petrochemical College, and the Scientific and Technological Research Equipment Center, Chulalongkorn University.

\section{References}

[1] Ministry of Science, Technology and Environment: Notification the Ministry of Science, Technology and Environment, No.3, B.E.2539 (1996) issued under the Enhancement and Conservation of the National Environmental Quality Act B.E.2535 (1992). The Royal Government Gazette, 113 Part13D, B.E.2539 (1996).

[2] Pesavento M., Biesuz R., Gallorini M., Profumo A.: Sorption mechanism of trace amounts of divalent metal ions on a chelating resin containing iminodiacetate groups. Analytical Chemistry, 65, 2522-2527 (1993). DOI: $10.1021 / \mathrm{ac00066a021}$

[3] Agrawal A., Sahu K. K.: Separation and recovery of lead from a mixture of some heavy metals using Amberlite IRC 718 chelating resin. Journal of Hazardous Materials, 133, 299-303 (2006). DOI: $10.1016 /$ j.jhazmat.2005.08.029 
[4] Lin L-C., Li J-K., Juang R-S.: Removal of Cu(II) and $\mathrm{Ni}(\mathrm{II})$ from aqueous solutions using batch and fixedbed ion exchange processes. Desalination, 225, 249259 (2008). DOI: 10.1016/j.desal.2007.03.017

[5] Liu R., Tang H., Zhang B.: Removal of Cu(II), Zn(II), $\mathrm{Cd}(\mathrm{III})$ and $\mathrm{Hg}$ (II) from waste water by poly(acrylaminophosphonic)-type chelating fiber. Chemosphere, 38, 3169-3179 (1999).

DOI: $10.1016 / \mathrm{S} 0045-6535(98) 00506-2$

[6] Hubicki Z., Leszczyńska M., Łodyga B., Łodyga A.: Palladium(II) removal from chloride and chloridenitrate solutions by chelating ion-exchangers containing N-donor atoms. Minerals Engineering, 19, 13411347 (2006).

DOI: $10.1016 /$ j.mineng.2006.01.004

[7] Egawa H., Nakayama M., Nonaka T., Sugihara E.: Recovery of uranium from sea water. IV. Influence of crosslinking reagent of the uranium adsorption of macroreticular chelating resin containing amidoxime groups. Jounal of Applied Polymer Science, 33, 1993 2005 (1987). DOI: 10.1002/app.1987.070330613

[8] Egawa H., Kabay N., Shuto T., Jyo A.: Recovery of uranium from seawater. XII. Preparation and characterization of lightly crosslinked highly porous chelating resins containing amidoxime groups. Journal of Applied Polymer Science, 46, 129-142 (1992). DOI: 10.1002/app.1992.070460113

[9] Liu X., Chen H., Wang C., Qu R., Ji C., Sun C., Zhang Y.: Synthesis of porous acrylonitrile/methyl acrylate copolymer beads by suspended emulsion polymerization and their adsorption properties after amidoximation. Journal of Hazardous Materials, 175, 1014-1021 (2010).

DOI: $10.1016 /$ j.jhazmat.2009.10.111

[10] Dominguez L., Yue Z., Economy J., Mangun C. L.: Design of polyvinyl alcohol mercaptyl fibers for arsenite chelation. Reactive and Functional Polymers, 53, 205-215 (2002).

DOI: $10.1016 / \mathrm{S} 1381-5148(02) 00174-8$

[11] Liu R. X., Zhang B. W., Tang H. X.: Synthesis and characterization of poly(acrylaminophosphonic-carboxyl-hydrazide) chelating fibre. Reactive and Functional Polymers, 39, 71-81 (1999).

DOI: $10.1016 / \mathrm{S} 1381-5148(97) 00174-0$

[12] Gong B.: Synthesis of polyacrylaminoimidazole chelating fiber and properties of concentration and separation of trace $\mathrm{Au}, \mathrm{Hg}$ and $\mathrm{Pd}$ from samples. Talanta, 57, 89-95 (2002). DOI: 10.1016/S0039-9140(02)00005-X

[13] Gong B., Li X., Wang F., Xu H., Chang X.: Synthesis of polyacrylacylaminourea chelating fiber and properties of concentration and separation of trace metal ions from samples. Analytica Chimica Acta, 427, 287-291 (2001).

DOI: $\underline{10.1016 / \mathrm{S} 0003-2670(00) 01198-3}$
[14] Chang X., Su Q., Liang D., Wei X., Wang B.: Efficiency and application of poly(acryldinitrophenylamidrazone-dinitroacrylphenylhydrazine) chelating fiber for pre-concentrating and separating trace $\mathrm{Au}(\mathrm{III})$, $\mathrm{Ru}(\mathrm{III}), \mathrm{In}(\mathrm{III}), \mathrm{Bi}(\mathrm{III}), \mathrm{Zr}(\mathrm{IV}), \mathrm{V}(\mathrm{V}), \mathrm{Ga}(\mathrm{III})$ and Ti(IV) from solution samples. Talanta, 57, 253-261 (2002).

DOI: 10.1016/S0039-9140(02)00032-2

[15] Chang X., Yang X., Wei X., Wu K.: Efficiency and mechanism of new poly(acryl-phenylamidrazone phenylhydrazide) chelating fiber for adsorbing trace $\mathrm{Ga}, \mathrm{In}, \mathrm{Bi}, \mathrm{V}$ and Ti from solution. Analytica Chimica Acta, 450, 231-238 (2001). DOI: $10.1016 / \mathrm{S} 0003-2670(01) 01387-3$

[16] Chang X., Li Y., Zhan G., Luo X., Gao W.: Synthesis of poly $(N$-aminoethyl)acrylamide chelating fiber and properties of concentration and separation of noble metal ions from samples. Talanta, 43, 407-413 (1996). DOI: 10.1016/0039-9140(95)01732-1

[17] Soldatov V. S., Shunkevich A. A., Elinson I. S., Johann J., Iraushek H.: Chemically active textile materials as efficient means for water purification. Desalination, 124, 181-192 (1999).

DOI: 10.1016/S0011-9164(99)00103-4

[18] Liao X., Ma H., Wang R., Shi B.: Adsorption of $\mathrm{UO}_{2}{ }^{2+}$ on tannins immobilized collagen fiber membrane. Journal of Membrane Science, 243, 235-241 (2004). DOI: 10.1016/j.memsci.2004.06.025

[19] Nishiyama S-Y., Saito K., Saito K., Sugita K., Sato K., Akiba M., Saito T., Tsuneda S., Hirata A., Tamada M., Sugo T.: High-speed recovery of antimony using chelating porous hollow-fiber membrane. Journal of Membrane Science, 214, 275-281 (2003). DOI: 10.1016/S0376-7388(02)00558-6

[20] Yuan Y., Zhao Y., Li H., Li Y., Gao X., Zheng C., Zhang J.: Electrospun metal oxide- $\mathrm{TiO}_{2}$ nanofibers for elemental mercury removal from flue gas. Journal of Hazardous Materials, 227-228, 427-435 (2012). DOI: 10.1016/j.jhazmat.2012.05.003

[21] Irani M., Keshtkar A. R., Moosavian M. A.: Removal of cadmium from aqueous solution using mesoporous PVA/TEOS/APTES composite nanofiber prepared by sol-gel/electrospinning. Chemical Engineering Journal, 200-202, 192-201 (2012). DOI: $10.1016 /$ j.cej.2012.06.054

[22] Zhang C., Li X., Bian X., Zheng T., Wang C.: Polyacrylonitrile/manganese acetate composite nanofibers and their catalysis performance on chromium (VI) reduction by oxalic acid. Journal of Hazardous Materials, 229-230, 439-445 (2012). DOI: $10.1016 /$ j.jhazmat.2012.05.085

[23] Taha A. A., Wu Y-N., Wang H., Li F.: Preparation and application of functionalized cellulose acetate/silica composite nanofibrous membrane via electrospinning for $\mathrm{Cr}(\mathrm{VI})$ ion removal from aqueous solution. Journal of Environment Management, 112, 10-16 (2012). DOI: $10.1016 /$ j.jenvman.2012.05.031 
[24] Ramakrishna S., Fujihara K., Teo W-E., Yong T., Ma Z., Ramaseshan R.: Electrospun nanofibers: Solving global issues. Materials Today, 9, 40-50 (2006). DOI: 10.1016/S1369-7021(06)71389-X

[25] Kampalanonwat P., Supaphol P.: Preparation and adsorption behavior of aminated electrospun polyacrylonitrile nanofiber mats for heavy metal ion removal. ACS Applied Materials and Interface, 2, 3619-3627 (2010).

DOI: $10.1021 / \mathrm{am} 1008024$

[26] Kampalanonwat P., Supaphol P.: Preparation of hydrolyzed electrospun polyacrylonitrile fiber mats as chelating substrates: A case study on copper(II) ions. Industrial and Engineering Chemistry Research. 50, 11912-11921 (2011). DOI: $10.1021 / \mathrm{ie} 200504 \mathrm{c}$

[27] Reneker D. H., Yarin A. L.: Electrospinning jets and polymer nanofibers. Polymer, 49, 2387-2425 (2008). DOI: $10.1016 /$ j.polymer.2008.02.002

[28] Sill T. J., von Recum H. A.: Electrospinning: Applications in drug delivery and tissue engineering. Biomaterials, 29, 1989-2006 (2008).

DOI: 10.1016/j.biomaterials.2008.01.011

[29] Shin Y. M., Hohman M. M., Brenner M. P., Rutledge G. C.: Experimental characterization of electrospinning: The electrically forced jet and instabilities. Polymer, 42, 9955-9967 (2001). DOI: 10.1016/s0032-3861(01)00540-7

[30] Saeed K., Haider S., Oh T-J., Park S-Y.: Preparation of amidoxime-modified polyacrylonitrile (PAN-oxime) nanofibers and their applications to metal ions adsorption. Journal of Membrane Science, 322, 400-405 (2008). DOI: 10.1016/j.memsci.2008.05.062

[31] Sang Y., Li F., Gu Q., Liang C., Chen J.: Heavy metalcontaminated groundwater treatment by a novel nanofiber membrane. Desalination, 223, 349-360 (2008). DOI: $10.1016 /$ j.desal.2007.01.208

[32] Ma Z., Masaya K., Ramakrishna S.: Immobilization of cibacron blue F3GA on electrospun polysulphone ultra-fine fiber surfaces towards developing an affinity membrane for albumin adsorption. Journal of Membrane Science, 282, 237-244 (2006). DOI: $10.1016 /$ j.memsci.2006.05.027
[33] Yarin A. L., Koombhongse S., Reneker D. H.: Taylor cone and jetting from liquid droplets in electrospinning of nanofibers. Journal of Applied Physics, 90, 4836-4846 (2001). DOI: $10.1063 / 1.1408260$

[34] Doshi J., Reneker D. H.: Electrospinning process and applications of electrospun fibers. Journal of Electrostatics, 35, 151-160 (1995).

DOI: 10.1016/0304-3886(95)00041-8

[35] Wannatong L., Sirivat A., Supaphol P.: Effects of solvents on electrospun polymeric fibers: Preliminary study on polystyrene. Polymer International, 53, 18511859 (2004).

DOI: $10.1002 /$ pi.1599

[36] Reneker D. H., Yarin A. L., Fong H., Koombhongse S.: Bending instability of electrically charged liquid jets of polymer solutions in electrospinning. Journal of Applied Physics, 87, 4531-4547 (2000).

DOI: $10.1063 / 1.373532$

[37] Jarusuwannapoom T., Hongrojjanawiwat W., Jitjaicham S., Wannathong L., Nithitanakul M., Pattamaprom C., Koombhongse P., Rangkupan R., Supaphol P.: Effect of solvents on electro-spinnability of polystyrene solutions and morphological appearance of resulting electrospun polystyrene fibers. European Polymer Journal, 41, 409-421 (2005). DOI: $10.1016 / j$.eurpolymj.2004.10.010

[38] Pattamaprom C., Hongrojjanawiwat W., Koombhongse P., Supaphol P., Jarusuwannapoo T., Rangkupan R.: The influence of solvent properties and functionality on the electrospinnability of polystyrene nanofibers. Macromolecular Materials and Engineering, 291, 840-847 (2006). DOI: $10.1002 / \mathrm{mame} .200600135$

[39] Park S-J., Im S-H.: Electrochemical behaviors of PAN/Ag-based carbon nanofibers by electrospinning. Bulletin of the Korean Chemical Society, 29, 777-781 (2008). DOI: $10.5012 / \mathrm{bkcs} .2008 .29 .4 .777$ 